\title{
Performative Technologies: Agricultural Research for Development and Gender
}

\author{
Maitrayee Mukhopadhyay \\ Royal Tropical Institute (KIT) \\ m.mukhopadhyay@kit.nl \\ Elisabeth Prügl \\ Graduate Institute, Geneva \\ elisabeth.prueg1@graduateinstitute.ch
}

This as an Accepted Manuscript of an article published by Taylor \& Francis in International Feminist Journal of Politics 21, 5 (2019), available online at https://doi.org/10.1080/14616742.2018.1555004 


\section{Abstract}

The article draws on insights from feminist literature, science and technology studies (STS) and governmentality studies to explore how technologies introduced through agricultural research for development (ar4d) participate in performing gender. Drawing on gender audits of two international agricultural research institutions, we discuss the performativity of three types of technologies: material technologies intended to increase agricultural productivity, such as new seed varieties; social technologies, such as household surveys and evaluation techniques used to monitor projects; and political technologies, such as participation, deployed to enlist farmers in the adoption of productivity-enhancing material technologies. We show that all three technologies participate in performing gender as they are introduced into rural environments, sometimes in interaction with an "apparatus of gender" that emerges from gender mainstreaming. But performances are not uniform, producing both an iron cage of hierarchical gender dualism, but also enactments that exceed the vision of the apparatus, blur binaries, and diffract the realities they project in unanticipated directions.

\section{Keywords}

Agricultural technology; gender and development; science and technology studies (STS) 


\section{Performative Technologies: Agricultural Research for Development and Gender}

Technology is not gender-neutral. Feminists looking at agricultural modernization through a gender lens in the 1980s saw that the introduction of new technologies, such as new seed varieties, or corn mills or mechanized tools, at best tended to displace women from agriculture and at worst cause them to lose an independent source of income. They argued that women and men use different technologies and that development efforts needed to improve also women's technologies. Gender-sensitive technology would ensure that women and men benefitted more evenly from development (Agarwal 1983; 1985; Stamp and IDRC 1989). But with the shift to a gender and development (GAD) approach since the 1990s, the focus on technologies seemed to slip off the feminist development agenda. The constructivist ontology of the GAD approach appeared to be incompatible with the sometimes essentialist assumptions inherent in arguments about the masculinity of technology or about masculine and feminine tools. Thus, as the GAD approach shifted the attention from modernization to the gendered power relations emerging from the differential insertion of women and men in capitalist and patriarchal structures, technology receded from the feminist view.

Our interest in this paper is to revisit the old feminist questions on the relationship between gender and technology in development. But rather than asking about the gendered impacts or uses of technology, we want to develop the constructivist perspective that is inherent in the GAD approach to show how 
contemporary agricultural technologies participate not only in (re)constructing gender, but also in performing gender. In other words, we acknowledge that the material world itself is an actor that participates in creating gendered realities; that this agency is usefully conceived of as part of a performance of gender. We believe that it is opportune to re-engage these issues today as gender has emerged as a topic in the field of agricultural research.

In the 1970s, as agricultural policy shifted from an obsession with increasing productivity to recognizing the importance of distributive measures and the need to support small-scale farmers, agronomists began to integrate social science knowledge into their research so that they could better understand technology adoption by these farmers. However, in the context of the neoliberal revolution of the 1980s both agriculture and distributive concerns receded into the background ${ }^{1}$. After decades of neglect, international development funders in the new millennium have resurrected the agricultural sector as a major source of livelihood for millions in the developing world. The publication of the World Development Report 2008, the global strategy for agriculture, introduced the concept of agriculture for development, bringing back a concern with agricultural productivity, and identifying the problem to lie in small farmers' lack of access to technology and markets. Small farmers no longer needed redistribution, but needed to be empowered to participate in markets.

\footnotetext{
${ }^{1}$ Beginning the 1980s there has been extensive experimentation with the liberalisation of the agricultural sector 'through the removal of guaranteed prices and export crop controls, the dismantling or cutting back on public provisioning to farmers (marketing, credit, inputs, infrastructure and other services), and the boost given to corporate farming for export' (Razavi 2009: 3).
} 
Agriculture research has become key to generating, testing and disseminating technologies that would revolutionize smallholder farming. Labeled "agricultural research for development" (ar4d), it includes socio-economic research whose role it is to examine technology adoption by farmers and to measure their productivity. Embedded in a neoliberal development paradigm, ar4d institutions seek to integrate research with change strategies by focusing on marketpropelled innovations, monitoring themselves by continuously measuring the outcomes of their interventions, but also systematically incorporating into the research process non-scientific stakeholders (Thornton et al. 2017; Maru et al. 2016; Adekunle et al. 2013; Okali 2012; World Bank 2007). Because ar4d strongly focuses on learning, some have argued that it provides a unique opportunity to integrate a transformative gender perspective (Kantor, Morgan, and Choudhury 2015). Indeed, funders have increasingly pushed international and national agricultural research institutions to mainstream gender into their work. There is now a significant body of research on gender in agriculture, and a plethora of gender analysis frameworks and tools to support such mainstreaming (Quisumbing et al. 2014; FAO 2011; World Bank, FAO and IFAD, 2008).

Agricultural research for development is carried out by international research institutions but also by national and regional ones. By far the largest and most influential is the international network of scientists gathered around the Consultative Group on International Agricultural Research (CGIAR), a consortium of fifteen independent research centers whose mission it is to help enhance food security in developing countries by coordinating the efforts of 
those who fund research with those who do research. With funding from national governments and private foundations held in trust by the World Bank, CGIAR also receives resources for programmatic work and specific research from international donors. The USAid and the Gates Foundation were the largest donors in 2016 (CGIAR 2016). The consortium employs about 11,000 staff that work closely with other scientists worldwide, many located in the numerous national and regional agricultural research centers that share the CGIAR mission (Okali 2012). It thus constitutes the core of a global knowledge network whose combined expertise informs agricultural development efforts, crucially shaping agricultural policies and indeed participating in "governing" such efforts (Ilcan and Phillips 2008).

The expertise of this network is the focus of our analysis in this article. Specifically, we examine the way this expertise is deployed through material and social technologies. We draw on data from two gender audits of ar4d projects and organizations completed 2013 in which one of the co-authors participated (reference eliminated for anonymity). The two audits do not constitute case studies of particular projects, countries, or regions. Rather, they provide us entry points to understanding the application of a particular kind of expertise to agricultural development in diverse sites. The first audit was of the International Maize and Wheat Improvement Centre (known by its Spanish acronym, CIMMYT), a member of the CGIAR consortium. The second audit was of the Association for Strengthening Agricultural Research in Eastern and Central Africa (ASARECA), an umbrella organization of national agricultural research systems from eleven states in the region. The two centers are located very 
differently in the international scientific network that constitutes ar4d, allowing us to probe similarities in performances in sites at a considerable distance from each other. CIMMYT is the largest center in the CGIAR consortium, and we narrow our focus on one of its programs, the Cereal Systems Initiative for South Asia program in Bangladesh (CSISA-BD), in which CIMMYT collaborated with two other CGIAR centers - the International Rice Research Institute (IRRI) and WorldFish (which specializes in acquaculture). ASARECA is located in Africa, the region that receives the largest amount of ar4d funding from CGIAR. We take the two centers as nodes participating in a global performance of expertise on agriculture, including gender and agriculture.

The purpose of the audits was to examine whether mainstreaming has been successful in ar4d, that is it was different from ours in this paper. However, the idea of pushing the questioning beyond the original agenda emerged during data analysis. The audits produced a large body of data, which can be used to provide insight into the ways in which ar4d technologies perform gender. Research included online surveys with staff, a desk review of project documents, interviews and focus groups with staff, project partners and women and men farmers. Materials used in this paper are drawn primarily from the qualitative data collected in the audits.

In the following, we first situate our paper in the literature and offer our understanding of what we mean by technology being performative. We then show how material technologies developed to increase agricultural productivity, such as new seed varieties or the "weed pusher," participate in the performance 
of gender divisions of labor and their destabilization. Subsequently we look at two social technologies, household surveys and log frames, and show how their design enacts the male household head and a binary gender order. Finally, we explore a political technology, participation, and show how it can disturb gender orders.

\section{Theoretical Framework}

How do technologies developed and deployed through ar4d participate in (re)constructing gender? In order answer the question we situate our study in existing feminist literature, science and technology studies (STS), and governmentality studies. There is not room in this paper to expand on this literature in depth, but we provide a quick review of core ideas that let us argue the performativity of technology, the implication of science and technology in the performance of gendered realities, and of gender expertise itself as a performative apparatus.

Feminists have long been intrigued by the way technology is coded masculine and observed male fascination with engineering and machinery (Holth and Mellström 2011; Saugeres 2002). Writing from a Marxist perspective, Cynthia Cockburn has argued that technology is an extension of bodily physique, and that its appropriation by men contributes to women's subordination and indeed is constitutive of women (Cockburn 1981, 1985, 2009). In development studies, Ester Boserup similarly associated new technology with masculinity: "it is usually the men who learn to operate the new types of equipment while women continue to work with the old hand tools" (Boserup 1970, 53). Other scholars 
highlighted that women and men use, and as a result value, different kinds of technologies, with women's technologies rarely receiving attention from scientists. These critiques led to a focus on the detrimental impacts on women of the introduction of new technology, often painting women as its victims. But feminists also have been wary of the essentialist implications of assuming a static gender division of labor and associating new technology with masculinity: Do not gender divisions of labor change? Should not the interactions between technologies and embodied individuals, and perhaps the co-constitution between them, be interrogated more closely? Do not artifacts themselves have gender? These kinds of questions led some feminist scholars to science and technology studies, arguing that the approach resonates with a feminist constructivist understanding of the world (Wajcman 2013, 2000; Campbell 2009; Berg and Lie 1995).

Feminist science and technology studies abandon a conception of technology as neutral, producing unanticipated effects in gender-unequal societies. Instead, they approach technology as itself participating in performing gender. The notion of the performativity of gender is of course familiar to feminists from Judith Butler's writings (1990; 1988). Butler's concern was to make visible the way gendered subjects and bodies materialize from performative acts and stylized repetitions. Moving beyond Butler, feminist post-humanists have proposed an ontological erasure of boundaries between humans, nature and technology (Braidotti 2013; Haraway 1989, 1985). In this understanding technology and nature have agency and are performative in the sense that they participate in creating phenomena in interaction with humans. We draw 
selectively on this literature in order to illustrate the different ways in which material, social and political technologies of ar4d participate in the performance of gender.

According to science and technology studies, material technologies are brought into being in laboratories and unleash their generative powers in interactions. We can think of such technologies as gendered because they are designed in gendered contexts and expert communities. Once offered for adoption, the power relations of knowledge production may no longer be visible in machines and seeds, yet they define the kinds of interactions they invite, and what they are able to do, i.e. how they become performative. Actor network theorists have made such interactions visible in multiple empirical studies from scallops farming to strawberry markets (Woolgar and Lezaun 2013; Latour 1987; Callon 1984, 1998). In these studies, non-humans (technology and nature) appear as "actants" that engage with other (human and non-human) actants to produce new realities. We postulate that agricultural technologies similarly interact with material and social worlds, and that they perform gender as they propel the power relations inscribed in them in their various interactions.

Social technologies appear in ar4d as apparatuses of measurement that gauge how farmers adopt new material technologies and monitor project implementation. In her "post-humanist performative account of the production of material bodies" Karen Barad imputes agency to such apparatuses: they make phenomena visible by measuring them and in this way participate in performing 
them (Barad 2003). ${ }^{2}$ These apparatuses resemble the proliferating indicators in international governance, which de facto bring into being international phenomena by measuring them, from "state fragility" to "vaccine coverage," and from "business climates" to "human rights" (Davis et al. 2012; Merry 2011; Rosga and Satterthwaie 2009; Löwenheim 2008). Some feminists have argued that gender similarly can be treated as an apparatus because it sorts people along a binary which it helps materialize. In this vein, Donna Haraway (1988) has called gender an "apparatus of bodily production." The feminist project of gender mainstreaming has become a distinctive aspect of the apparatus of gender often reproducing the hetero-normative binary through its various instruments of expertise.

Barad's apparatuses bear a family resemblance to Foucault's "technologies of government." Feminists have extensively drawn on Foucault to explore gender as an apparatus and as a set of technologies (e.g. Repo 2015; Mukhopadhyay 2014; Prügl 2011; de Lauretis 1987). Against the treatment of technologies and apparatuses in STS, governmentality studies bring into view political projects and goals that technologies propel. Technologies of government help establish a link between broad political rationalities on the one hand and the minutiae of daily existence and practices of administration on the other. They encompass statistics and mapping to administer populations (Rose and Miller 1992; Foucault 1991); the range of tools managing the everyday practice of government, such as the surveys and log frames of ar4; but also importantly, the political technology of participation. From a governmentality perspective,

\footnotetext{
2 Thus, for example, whether light appears as a wave or particle depends on the way it is measured and with what apparatus, but it has reality in both forms.
} 
participation has become a technology of governance because, by seeking consent for governmental interventions from population groups, it contributes to their regulation (Djelic and Sahlin-Andersson 2006). However, as Chatterjee (2004: 69) suggests, "participation has one meaning when it is seen from the standpoint of those who govern, i.e., as a category of governance. It will have a very different meaning when seen from the position of the governed, i.e., as a practice of democracy." Thus, participation (and perhaps political technologies more broadly) both fits and exceeds the meanings of technology offered in this paper.

Assuming that technology is gendered by design does not mean that its effects are pre-ordained. As technologies interact and are appropriated, they are often reinvented for unintended purposes (Eglash 2004). Literature shows that "unconventional performances" are frequent as women (and men) live up to idealized public identities more or less faithfully and in ways that shift over time (Galiè et al. 2017, 5; Doss 2002). Thus the deployment of technologies, including gender technologies, may produce sometimes-surprising results.

\section{Material Technologies: Performing Gender in Interaction}

Despite increasing attention to gender issues in international development circles, technology continues to displace women from agriculture, just as it has done in the past. For example, in southern Bangladesh the introduction of hybrid maize varieties, a new crop in the region, by the CSISA-BD CIMMYT scientists eliminated the need for seed preservation because hybrid maize seed needs to be 
purchased every year. The technology de facto has abolished a task commonly associated with women and thus contributed to diminishing women's productive role in agriculture. The design of hybrid seed technology in this sense is masculine, though it is important to recognize that it reduces the autonomy of all farmers regardless of gender. Its performativity emerges in interaction, including with scientists increasingly sensitized to gender. The outcomes vary accordingly.

A first performance is of the gender division of labor. The scientists interviewed in Bangladesh were aware of women's displacement and puzzled over how to "involve" them in order to fulfill the mandate of addressing gender inequality. Their answer lay in focusing on women's "domestic" tasks and developing technologies to make these tasks more productive. Gender here ended up operating as an apparatus: it made women visible as the binary other that maps onto the dichotomy of public and domestic.

Latched onto gender in this way agricultural technologies participated in performing the gender division of labor. The researchers in the CSISABangladesh project partitioned agricultural technologies, knowledge and information into domestic and public. The intent was to counter the previous neglect of women, but they did so in a distinctly binary way, isolating the agriculture-related tasks in the homestead, identifying them as feminine, and providing the technologies to make these more productive. For WorldFish this entailed the promotion of technologies for horticulture and cage agriculture in and around household based ponds; for IRRI and CIMMYT it meant supporting post-harvest operations, mainly rice and wheat seed preservation. In the words of one CIMMYT respondent: 
And in our planning cycle last year, I was conscious that we weren't really as CIMMYT targeting women enough in terms of how we were doing things. So I definitely was emphasizing to our hub managers that they should do more with the wheat seed production because that is one area that we know that women play a prominent role. (CSISA-BD CIMMYT respondent 1$)^{3}$

The approach gives rise to feminine activities and associated technologies-fish cages, horticulture and seed preservation-that target women in households, reproducing and indeed cementing the opposition between women's and men's work (Kantor et al 2015; ASARECA secretariat respondent 1). Agricultural technology comes to mirror the gender division of labor, and indeed it participates in enacting it. It helps keep in place the gender binary while hiding the multiple power relations that prop it up.

Part of the problem is the failure of scientists to recognize that gender relations are power relations. Instead they tend to extract what men and women do in agriculture from the relations in which these are embedded, which is what the GAD approach would suggest. This became explicit in the ASARECA gender audit (reference eliminated for anonymity). When asked about their understanding of gender relations and the relevance of these relations for ar4d, respondents most often described gender as the socially differentiated roles of women and men, and they saw its relevance for ar4d in being able to introduce technologies that could make these roles more productive. Their starting point thus was the gender division of labor as descriptive of the work of women and men, ignoring

\footnotetext{
${ }^{3}$ Respondents are numbered in order of appearance in this paper separately for ASARECA and CIMMYT
} 
the relations of hierarchy and control embedded in the division. Reduced to this technical understanding, gender equality can be addressed through technologies targeting women. But the approach also produces technologies that transport difference. The apparatus of gender thus does its work in interaction with agricultural technologies as high-yielding varieties replace traditional seed technologies, and new feminine technologies begin to complement those coded masculine.

Yet, technologies are not unambiguous and there is a second type of effects that emerged from their interaction with social actors, a destabilization of gender divisions of labor. Indeed, there is ample evidence in the literature that agricultural technologies can and do change men and women's roles. Often these changes are not for the benefit of women as men appropriate women's roles when they become profitable. The effect is that women's position worsens because they lose control over production and resources (Dey 1981; Carney and Watts 1999; Doss and Morris 2001).

But we also encountered instances where technology disturbs the gender division of labor and in particular the hierarchy embedded in it. Interestingly these happened outside a discourse of gender mainstreaming. One example is the story a scientist told about the weed pusher:

The rice programme, they came up with technology for weeding, what we call a weed pusher, whereby it is helping to weed the rice fields faster and you know rice, rice is shorter, at that time of weeding you need to bend. It is back-breaking work. Now, men said, "ahh ... I don't want to do this." So 
you find mostly women doing the weeding. But with the weed pusher you find that children are also assisting their mothers and also husbands because they don't need to bend. You do it while standing, so they are also assisting. So we found out that it is breaking that gender specificity that weeding is for women, no, now men are also coming in. We see the role of technology in terms of responding to some of the gender specific operations. (Resp. ASARECA Secretariat 1)

The weed pusher enabled an unscheduled performance: Men and children joining women in what used to be back-breaking work; the weed pusher not only inviting a violation of the gender division of labor but changing the gendered meaning of weeding. In so doing the technology becomes an "actant" emptying the act of weeding of its gendered meaning: it emerges as a potent actor capable of bringing about change in a neoliberalizing society increasingly imagined as consisting of atomized individuals choosing to profit from a technology.

\section{Social Technologies: Performing Gender through Measurement}

One innovation of ar4d is to pair the development of agricultural technologies with technologies from the social sciences to facilitate the introduction of new tools and techniques to communities and enable project monitoring and evaluation. Numerical methods predominate among these social technologies reflecting the fascination with and power of numbers that scholars have identified in policy expertise more broadly (e.g. Fioramonti 2014; Porter 1996). These technologies also reflect the episteme of the bio-physical and natural sciences and of development economics that form the core body of expertise of 
ar4d. The measurement tools emerging from these bodies of expertise have a family resemblance with the material technologies discussed in the sense that they transport gender biases that went into their creation. But they do more: they help constitute the phenomena that they pretend to measure, and they do so within a neoliberal logic of governmentality. Here we look more closely at two such technologies: the household survey and the measurement of project results.

\section{The Household Survey}

If gender is an apparatus that sorts people into female and male, the household survey is its handmaiden, a powerful numeric technology to inscribe social organization. It constructs the farming household as corporate and governed by a male head. Drawing on the neo-classical economists' rational choice theory, it is imagined as a unitary entity where production and consumption are integrated, resources and labor pooled and allocated on a rational basis for those activities that will produce the ideal bundle of goods. In this scenario the head of the household is conceived of as the benevolent dictator who must exercise authority to ensure welfare maximization (Kabeer 1994). This household renders women and their work utterly invisible. It falsifies what in essence are severe allocational deficiencies among members along gender, age and social relational lines (Folbre 1984a; 1984b). Moreover, it fails to account for the diverse forms of households and of people living together. And it does so virulently in ar4d survey technologies.

The CSISA-BD uses both household surveys and socio-economic surveys for demonstrations and crop trials. Both types of surveys inscribe the notion of a male household head who operates as the farm manager. The interviews with 
program officers and technical staff revealed that demonstrations and trials involved almost exclusively men, whom surveys constructed as the farmers while approaching women as "wives".

And we collect farmers' views about the technology tested in the field, why they choose this one and not another. Sometimes we also collect some views of the women besides the farmer, the farmer's wife, their information related to these activities. (CSISA-BD CIMMYT Respondent 2)

Thus it is mainly men's opinion that was surveyed on crop variety selection:

(Crop) varieties selection ... this is of similar importance to men and women. Here, we are not yet considering these things [meaning gender disaggregation]. We are generally doing the common questionnaire. Maximum we interview the men. (CSISA-BD CIMMYT Respondent 2)

Women were not directly asked about a new technology, and the questionnaires were not administered to both women and men on a routine basis. Women's opinions were gathered from the men's reporting. Feminist critiques of conceiving households as pooling and non-conflictual entities have barely dented the application of household surveys, which in this way participate in affirming male headship and neoliberal notions of household productivity through ar4d.

CIMMYT also provided us with an instance to observe the interaction of household surveys, an internationally used and relatively uniform technique, with local gender knowledge. Asked why women were not interviewed the respondent replied: "some religious minded or so (persons), if you want to ask some questions to the woman it will create problem (sic) for the male person" 
(CSISA-BD CIMMYT Respondent 2). Here the respondent deployed a well-known trope in the South Asian social and cultural imaginary about gender roles comprising of essentialisms of home/world, spiritual/material, feminine/masculine. This was present throughout the interviews in Bangladesh, whether in the partitioning of agriculture programs into public and private, in considering women as not belonging in the public sphere of work, or in women not being consulted in surveys. The etiology of this imaginary reaches back into the nineteenth century debates between the colonial powers and the Indian elite on women's status and its subsequent resolution in the twentieth century by nationalist discourses, which through this resolution sought to counter colonial domination. ${ }^{4}$

In the present we see this trope being played out in the encounter between international development agencies and Bangladesh on the question of gender often with religious overtones (Clisby and Enderstein 2017). The understanding of women as private, as "respectable," as belonging to their community is used as resistance against supposed neo-colonialism such as gender equality. But besides "safeguarding" women seen as respectable, it also invisibilises the

\footnotetext{
${ }^{4}$ The cultural construction of a new, modern woman to represent the new nation was achieved by separating the domain of culture into the material and spiritual spheres (Chatterjee 1989;

Mukhopadhyay 1998). In the material sphere the claims of the West were accepted as superior and to be imitated, and was men's domain. The spiritual sphere, imaged as representing the distinctive culture of the East, was designated female. This dichotomy in day-to-day life maintained an ideological separation of on the one hand the home, wherein resided Indian spirituality and authenticity, and on the other, the outer world of material pursuits. The distinctively Indian feature of this otherwise archetypical patriarchal dichotomy was that women as the keepers of the spiritual quality of the nation, had to be protected from becoming wholly westernized as men could which meant strictly monitoring their dress, education, manners, relations in the home and world. Thus "modern" did not imply the emergence of women as the autonomous subject of rights but rather as subjects of a reformed patriarchy. This prototypical respectable woman became the norm and a signifier of the emerging elite class and citizen othering thereby lower class women who could not fulfill this norm because of their life situation.
} 
concerns of those women who are in the public sphere of work in agriculture, specifically those who work in the fields.

The social technology of the household survey becomes complicit in reproducing this trope. By focusing on heads of households, it hides the agency of women in agriculture and precludes them from becoming agents in agriculture technology transfer. Indeed, it helps bring into being the reality of households headed by men in conjunction with "non-working" wives (compare Mies 2012). At same time, the figure of the head of households anchors calculations of productivity central to neoliberal development logics. The notion of respectable women belonging into the private sphere thus becomes an intrinsic part of such logics.

\section{Results Frameworks}

Like all development activities, ar4d needs to show that it achieves what it promises. It does so through planning tools such as "results frameworks" or "log frames" that have become commonplace in development planning. These technologies specify the goals of an intervention and identify the outcomes and outputs it needs to produce in order to achieve the goals together with indicators to measure these. Log frames have all the characteristics of an apparatus of measurement as described in science and technology studies because they produce the realities that they set out to measure, not least by disciplining practitioners to work towards their achievement (Eyben 2013). In other words, $\log$ frames are a technology characteristic of the "audit culture" that scholars have identified as characteristic for neoliberal governmentality, seeking to hold accountable through constant "rituals of verification" including self-monitoring, ranking, and evaluation (Strathern 2000). 
A numeric bias in measuring results leads these technologies to generate newly gendered realities: when gender needs to be measured, it is always broken down into "women and men;" the relational aspect of gender suggested in the GAD approach disappears. For example, in the annual report of CSISA-BD, gender appears as sex disaggregated participation numbers in training events or in an on-farm trial or demonstration (CSISA-BD Annual Report 2014). ASARECA similarly reported on gender in the semi-annual report by disaggregating participation according to women and men, and in the log frames by using indicators such as "more women on research consortia" (reference deleted for anonymity). Reducing measurement to counting imposes a gender binary grid and introduces a definition of gender as meaning women and men; gender as a relation of power is difficult to capture in numeric measurements of this sort.

There were some efforts in ASARECA log frames to construct more sophisticated indicators for gender integration, such as "number of gender sensitive innovations" and "number of institutional arrangements that enhance access to and use of 'program' resources by women and youth." Some strategic plans of programs measured gender in institutional outcomes with indicators such as "performance driven gender sensitive governance and management structures and systems established and operational" or "capacity for gender responsive agricultural research for development in the ECA sub region strengthened" (reference deleted for anonymity). The difficulty with these kinds of indicators lies in their definition: What are gender sensitive governance structures? What are gender sensitive innovations? In the words of one respondent: 
For example, we have an indicator that says gender responsive technologies generated. But there are no specific indicators to show how and what makes them gender responsive! (Resp. ASARECA secretariat 2)

As a technology of a neoliberal audit culture, log frames push towards evidence that can be provided in numbers, which encourages the translation of gender into the binary of women and men. They are thus gendered by design but also come to perform gender-the phenomenon they set out to measure. Rather than providing an opportunity for transformative gender mainstreaming this ar $4 \mathrm{~d}$ social technology, as was the case for household surveys, thus participates in stabilizing gender difference and also power relations.

\section{Participation: From Performative Technologies to Politics}

Whereas activists and social movements in the 1970s and 1980s argued for peoples' right to be consulted in development decisions, ${ }^{5}$ mainstream development agencies from 1970s on saw participation as an important tool to increase project effectiveness, efficiency and cost sharing (Cornwall 2002). Since then international institutions and donor bodies have made participation of stakeholders a standard feature of the governance of development. Some form of participation is a regular feature of most ar4d programs and is reported in results frameworks. Participation serves multiple functions, insuring projects

\footnotetext{
${ }^{5}$ See Shiva \& Bandyopadhyay on the 1970s Chipko movement in India a major social movement of forest dwellers; see also Escobar \& Alvarez (1992) on the 1980s new social movements in Latin America.
} 
against resistance or rejection but also providing a check on their administration (Chatterjee 2004). How does this technology participate in performing gender?

Participatory variety selection (PVS) is among the most frequently used participatory technologies of the CGIAR research programs. As with other technologies reviewed in this paper, it is prone to reproduce the gender division of labor. PVS enlists farmers in the evaluation of a particular crop variety according to criteria such as yield, maturity, cook-ability, taste, color, and pest resistance. Gender researchers have noted that although women and men prefer similar traits, they rank the traits according to their social roles, and women rank higher than men traits which have a direct bearing on their daily chores like cook-ability and taste (Ortiz-Ferrara et al. 2000). Gender experts have used this finding to convince scientists of the importance of disaggregating PVS by gender and of integrating gender into their research: Agriculture scientists can then breed seeds keeping in mind the preferred traits of women and men, and they can organize extension and training activities mindful of women's availability. PAV thus becomes a tool to design gender into agricultural technology, in the process reproducing existing gender divisions of labor.

But participation comes in different designs and may also disturb gender divisions, setting free plural logics. A case from southern Bangladesh illustrates this aspect of participation. The case involves a CIMMYT senior scientist who, when introducing new agriculture technologies and management practices, decided to target women in farming communities, invest in their knowledge and soliciting them as participants in the project to ensure technology adoption. In a 
deliberate inversion of the standard community mobilization practice of forming male farmer groups, the scientist formed women's groups in the research villages. In the case cited below the community is Hindu in a Muslim majority country ${ }^{6}$. The women are generally seen as less "traditional" than their Muslim counterparts but are nevertheless subject to the rules of appropriate female behavior. The community comprises small peasants whose socio-economic situation is not very different from that of the neighboring Muslim villages in that the income from farming has to be supplemented by the men (and in some cases women) working in other jobs. The social scientist's reasoning for targeting women was steeped in the gender binary, though he reversed accepted meanings. His starting point was to challenge the general perception of CIMMYT scientists that women in Bangladesh do not work in agriculture:

People give importance to something which is visible. When a male farmer works in the rain in the field, everyone observes it. On the other hand, when women give their labor for drying wheat or paddy, for threshing them and finally stocking them and preserving seeds for next year people can hardly see all these activities taking place in the homestead. Male or female-each of their labor is not less significant. (CSISA-BD CIMMYT respondent 3)

\footnotetext{
${ }^{6}$ Although intersectionality may seem not to be at the center of our analysis, it is nevertheless an integral part of the examples given, as gender does not exist outside of other social divisions: of class, race, caste, ethnicity, religion and nation. However, the way in which gender intersects with other social divisions is specific to histories and contexts. Thus in South Asia class and caste are major factors as is religion. To be a Hindu woman in a Muslim country or vice versa positions a woman in specific ways.
} 
In a second step the scientist claimed that women actually do most of the work, including field work, and constructed them as farmers, reversing existing valuations:

You will find men congregating at the market at the junction outside the village in the afternoons. They stay there till the evening chatting, drinking tea. Whereas all the women are still in the field in the afternoon doing this and that - herding the cattle, weeding etc. and then in the evening they rush home, light the lamps and start the evening cooking. So if you look at who does the work you see that the men start early but after 3-4 pm they don't want to work and they finish the working day whereas the women continue. That's why I think that most of the labor is put in by the women, they do far more work than the men. (CSISA-BD CIMMYT respondent 3)

This revaluation then demanded that women, because they did not own land but worked in agriculture, should be the keepers of the new scientific knowledge. In his project, women participated in the demonstration plots, learned how to measure, observe and experiment, do conservation farming and use farm machinery. They became leaders in the introduction of maize, wheat and rice technologies in the region.

Three years after the CIMMYT intervention there were a number of changes in the village. A third crop, hybrid maize, was added to crops already grown, rice and wheat. A major technical problem, salinity of the soil, was overcome through the introduction of new management practices. 
We are small peasants with small holdings and we got one (rice) crop a year. This land lay fallow. We didn't do anything with it. Then when CIMMYT came we learned that we could grow a new crop, which was maize. (CSISA-BD CIMMYT female respondent 1)

Asked how the village had benefited from the interventions brought by the program, the answers were clear: "People can now grow two to three crops thanks to CIMMYT" and "we have benefited economically."

Women's work also had increased manifold as a result of the disruption of the gender division of labor:

Our work has increased. We do everything: work in the field and work on the crops when they are brought home. Cultivation requires our work. Women are in great demand because we work side by side with the men. (CSISA-BD CIMMYT, female respondent 2).

But there were compensations: "when we saw that we could harvest the crops, bring the crops home to our homesteads and eat well we were filled with joy and this transformed us and we appreciated the change" (ibid). Importantly, the new knowledge and skills also had given women confidence:

Now we understand that when we did not have sufficient work in the fields, we were demoralized. We didn't understand what self-confidence was. And now that we have more work and more knowledge how the technology works we are mentally much stronger because we are confident that we can do this. (CSISA-BD CIMMYT, female respondent 3) 
More crops, economic benefits, more work but motivation to work, and eating well as a result. But also importantly a recognition that women are farmers and knowledgeable experts. The refrain "We do everything: work in the field and work on the crops when they are brought home" acquires new significance in a culture where women's work is not acknowledged by agriculture experts, families and even the women themselves. Indeed, women working in the field is associated in the wider culture with low status in a reproduction of the trope mentioned previously. For example, in focus group discussions women in a village in another district described a variety of activities that they had to undertake on a daily and seasonal basis, including work on the field. However, when asked directly about on-field work there was lots of hesitation, and one woman said that "it had not come to that," meaning that the circumstances were not so bad that women had to become dishonorable by working in the fields. ${ }^{7}$ In light of such attitudes, the fact that women in the first village prided themselves for their work was remarkable, enabled through a participatory process that made them the principals in the adoption of masculine-coded hybrid seed technology.

Another oft repeated phrase was about gaining knowledge, which must be interpreted as women becoming subjects. No longer were they invited to training programs and extension activities as part of families, but as legitimate agriculturalists. More than that, four women were selected to work as peer educators and experts in wheat, maize, rice and vegetables and travelled widely to attend sessions organized for farmer groups. They had in essence what

\footnotetext{
${ }^{7}$ Reference eliminated for anonymity.
} 
amounts to an independent life outside of the village, outside their roles as farmers' wives. That a certain degree of democratization resulted from growing personhood could be seen in the interactions between them and the young, male project officers and with their own men. A project officer related an incident in which Dipali, a widow with little land, had solved a tricky technical problem in rice seed planting by anticipating the problems and correcting the project officer's methods so that he was forced to acknowledge her superior expertise: "We managed to solve many technical problems thanks to Dipali didi ${ }^{8}$ who always anticipated the problem." Before he could do so,

they (the women) had already done the seed planting in the most scientific and systematic manner. How to irrigate the seedlings, how to keep them upright. All these day-to-day problems they handled and they made suggestions (CSISA-BD CIMMYT male project officer 1)

One could interpret this story as women buying into the discourse that the expert knowledge of scientists is the only thing that stands between them and progress, and there is a whiff of patriarchal benevolence in the narrative of the heroic scientist and his apprentice. But there is something more interesting going on here: Women embracing male-coded hybrid seed technology, an outcome enabled by yet another technology, i.e. participation designed in a way to mobilize women to adopt the new seeds. Gendered power relations are definitely disturbed in this interaction.

A male farmer who besides owning some land also has a small tailoring business, when asked about his wife's role said, "I don't have to worry at all about the

\footnotetext{
${ }^{8}$ Respectful address for elder sister
} 
shongsar (a term generally used to mean household work and often encompassing the agricultural work of both women and men). She does everything" (CSISA-BD CIMMYT male respondent). This respondent's acknowledgement of his wife's role (she was the wheat expert) signaled the beginnings of democratization in what is the most intractable of power relations, i.e. gender. Participation unveiled itself as a technology capable of disrupting the binary gender order. It opened up the rigid field of vision offered through the apparatus of gender that sorts women and men hierarchically into spheres of public and private, productive and reproductive. In the Bangladesh context it broke through the trope of essentialisms of home/world, spiritual/material, feminine/masculine.

\section{Conclusion}

Our purpose in this paper has been to show that technology participates in the performance of gender. Technology is not just gendered in its use and impacts; instead gender and power relations go into its making and take effect in its interactions with other technologies and actors. Agricultural technologies that are created without regard for power relations privilege commercial interests producing seed against women's expertise with seed preservation. Tools created to increase the productivity of women's and men's tasks join people to enact the gender division of labor, as do exercises of participatory variety selection that limit women and men to their assigned gender roles. Social technologies such as household surveys are complicit in the construction of men as household heads and women as non-farmers and wives; and managerial technologies such as log 
frames that limit gender equality outcomes to counting women and men reaffirm gender as a binary.

Yet technology is not caught in a preordained gendered logic-it realizes its meaning in interactions with other technologies and social relations in a field of application. The story of the weed pusher showed how a technology developed for a low-status feminine-coded task can produce unintended effects. And the story of enlisting women as developers of scientific expertise showed how such participation opened astonishing possibilities for women in farming-moving beyond their reproduction as the farmer's wife or as the small-scale female farmer condemned to low-productivity activities.

Neoliberal logics of productivity, profitability and audit cultures inhabit the performances of gender in ar4d discussed in this paper. We believe there is a need for more research to shed light on these relationship and investigate the way material technologies are implicated in (re)constructing gender and reconstituting neoliberalism in parallel. To do so it is necessary to shift from a narrow political economy understanding of the relationship between gender and neoliberalism to recognizing the performativity of the material world and of various technologies in realizing neoliberal projects.

Ar4d does indeed provide a unique opportunity for infusing a transformative gender perspective into agriculture. But to do so, ar4d needs to move beyond a superficial application of the apparatus of gender in the technologies of gender mainstreaming. Instead, it needs to recognize that gender informs the 
conception, design, and deployment of technologies, that gender relations thus are inscribed into the technologies created, and that these relations become generative as technologies are deployed and as they interact with people and other technologies. Inserting gender into agriculture thus cannot stop at introducing seemingly neutral technologies to women; it needs to take the extra step of interrogating the technologies themselves together with their performativity. And this is true not only of agricultural tools and processes, but equally important of the social and political technologies that are supposed to enhance ar4d. The evidence from the two audits shows the particular promise of participation if it dares to disrupt traditional understandings about women's and men's work in agriculture and overcome masculinist and colonial imaginaries of what is possible. 


\section{Works Cited}

Adekunle, A., A. O. Fatunbi, R. Buruchara, and Sospeter Nyamwaro. 2013. "Integrated Agricultural Research for Development: From Concept to Practice." In Forum for Agricultural Research in Africa (FARA), Accra, Ghana. http://ciat-

library.ciat.cgiar.org/articulos_ciat/biblioteca/integrated_agricultural_res earch_for_development_from_concept_to_practice.pdf. Accessed August 10, 2017.

Agarwal, Bina. 1983. "Diffusion of Rural Innovations: Some Analytical Issues and the Case of Wood-Burning Stoves." World Development 11, no. 4 (April): 359-76.

-_- 1985. "Women and Technological Change in Agriculture: Asian and African Experience." In Technology and Rural Women: Conceptual and Empirical Issues, edited by Iftikhar Ahmed, 67-111. Geneva: ILO.

Barad, Karen. 2003. "Posthumanist Performativity: Toward an Understanding of How Matter Comes to Matter." Signs: Journal of Women in Culture and Society 28 (3): 801al of Women in Culture anButler, Judith. 1990. Gender Trouble: Feminism and the Subversion of Identity. New York: Routledge.

Berg, Anne-Jorunn, and Merete Lie. 1995. "Feminism and Constructivism: Do Artifacts Have Gender?" Science, Technology, \& Human Values 20, no. 3.

Boserup, Ester. 1970. Woman's Role in Economic Development. New York: St. Martin's Press.

Braidotti, Rosi. 2013. The Posthuman. John Wiley \& Sons.

Butler, Judith. 1990. Gender Trouble: Feminism and the Subversion of Identity. New York: Routledge.

- - 1 1988. "Performative Acts and Gender Constitution: An Essay in Phenomenology and Feminist Theory." Theatre Journal 40, no. 4 (December): 519-31.

Campbell, Nancy D. 2009. "Reconstructing Science and Technology Studies: Views from Feminist Standpoint Theory." Frontiers: A Journal of Women Studies 30, no. 1: 1-29.

Carney, Judith and Michael Watts. 1999. "Disciplining Women? Rice, Mechanisation, and the Evolution of Mandinka Gender Relations in Senegambia." Signs: Journal of Women in Culture and Society 16, 4: 651680.

Chatterjee, Partha. 1989 The Nationalist Resolution of the Women's Question. In Recasting Women: Essays in Colonial History edited by Kumkum Sangari \& Sudesh Vaid. 233-254. New Delhi:Kali for Women

Chatterjee, Partha. 2004. The Politics of the Governed: Reflections on Politics in Most of the World. New York: Columbia University Press.

Clisby, Suzanne and Athena-Maria Enderstein. 2017. "Caught between the orientalist-occidentalist polemic: gender mainstreaming as a feminist transformation or neocolonial subversion?" Feminist Journal of Politics, Vol. 19, No.2, 231-246

Cornwall, Andrea. 2002. "Locating Citizen Participation" IDS Bulletin, 33-2, i-x. 
Boserup, Ester. Woman's Role in Economic Development. London: Earthscan, 2007.

CGIAR. 2016. CGIAR Financial Report. CGIAR website at https://cgspace.cgiar.org/bitstream/handle/10947/4666/2016-CGIARFinancial-Report.pdf?sequence=1. Accessed June 26, 2018.

Cockburn, Cynthia. 1981. "The Material of Male Power." Feminist Review, no. 9: 41-58.

———. 1985. Machinery of Dominance: Women, Men and Technical Know-How. Pluto Press.

- - 2009. "On the Machinery of Dominance: Women, Men, and Technical Know-How." WSQ: Women's Studies Quarterly 37 (1): 269-273.

Davis, Kevin E., Angelina Fisher, Benedict Kingsbury, and Sally Engle Merry, eds. 2012. Governance by Indicators: Global Power Through Classification and Rankings. OUP Oxford.

De Lauretis, Teresa. 1987. Technologies of Gender: Essays on Theory, Film, and Fiction. Theories of Representation and Difference. Bloomington: Indiana University Press.

Dean, Mitchell. 2010. Governmentality: Power and Rule in Modern Society. 2nd ed. Los Angeles: SAGE.

Dey, Jennie. 1981. "Gambian Women: Unequal Partners in Rice Development Projects?" In African Women in the Development Process, ed. Nicki Nelson. Oxon and New York: Frank Cass.

Djelic, Marie-Laure, and Kerstin Sahlin-Andersson. 2006. "Transnational Governance in the Making -- Regulatory Fields and Their Dynamics." In Transnational Governance: Institutional Dynamics of Regulation, eds. Marie-Laure Djelic and Sahlin-Andersson. Cambridge University Press.

Doss, Cheryl. 2002. "Men's Crops? Women's Crops? The Gender Patterns of Cropping in Ghana." World Development 30 (11): 1987-2000.

Doss, Cheryl R. and Michael L. Morris. 2001. "How Does Gender Affect the Adoption of Agricultural Innovations? The Case of Improved Maize Technology in Ghana," Agricultural Economics 25 (1): 27-29.

Eglash, Ron. 2004. Appropriating Technology: Vernacular Science and Social Power. Minneapolis: University of Minnesota Press.

Escobar, Arturo, and Sonia E. Alvarez 2018. "Introduction: Theory and Protest in Latin America." In Arturo Escobar and Sonia E. Alvarez The Making of Social Movements in Latin America: Identity, Strategy and Democracy. Reprinted by Routledge New York.

Eyben, Rosalind. 2013. Uncovering the Politics of "Evidence" and "Results". A Framing Paper for Development Practitioners. http://bigpushforward.net/wp-content/uploads/2011/01/The-politicsof-evidence-11-April-20133.pdf. Accessed December 3, 2017.

FA0. 2011. Women in Agriculture: Closing the Gender Gap for Development. The State of Food and Agriculture 2010/11. Rome: FAO.

Fioramonti, Lorenzo. How Numbers Rule the World: The Use and Abuse of Statistics in Global Politics. London: Zed Books, 2014.

Folbre, Nancy. 1984a. "Market Opportunities, Genetic Endowments and Intrafamily Resource Distribution: Comment." American Economic Review 74 (3): 518-520.

----- 1984b. "Household Production in the Phillipines: A Non-neoclassical 
Approach." Economic Development and Cultural Change 32 (2): 303-330. Foucault, Michel. 1991. Governmentality. In The Foucault Effect: Studies in Governmentality, Eds. Graham Burchell, Colin Gordon and Peter Miller, 87-104. University of Chicago Press.

Galiè, Alessandra, Janice Jiggins, Paul C. Struik, Stefania Grando, and Salvatore Ceccarelli. 2017. “Women's Empowerment through Seed Improvement and Seed Governance: Evidence from Participatory Barley Breeding in Pre-War Syria." NJAS - Wageningen Journal of Life Sciences 81 (June): 1-8. Haraway, Donna. 1985. 'A Manifesto for Cyborgs: Science, Technology, and Socialist Feminism in the 1980s'. Socialist Review 15 (2): 65-108. . 1988. 'Situated Knowledges: The Science Question in Feminism and the Privilege of Partial Perspective'. Feminist Studies 14 (3): 575-99.

- - - 1989. Primate Visions: Gender, Race, and Nature in the World of Modern Science. Psychology Press.

Holth, Line, and Ulf Mellström. 2011. "Revisiting Engineering, Masculinity and Technology Studies: Old Structures with New Openings". International Journal of Gender, Science and Technology 3 (2): 313-329.

Ilcan, Suzan, and Lynne Phillips. 2008. "Governing through Global Networks: Knowledge Mobilities and Participatory Development." Current Sociology 56, no. 5 (September 1): 711-34.

Kabeer, Naila. 1994. "Benevolent Dictators, Maternal Altruists and Patriarchal Contracts: Gender and Household Economic." In Reversed Realities: Gender Hierarchies in Development Thought, by Naila Kabeer, pp. 95-135. London and New York: Verso.

Kantor, Paula, Miranda Morgan, and Afrina Choudhury. 2015. “Amplifying Outcomes by Addressing Inequality: The Role of Gender-Transformative Approaches in Agricultural Research for Development." Gender, Technology and Development 19 (3): 292-319.

Landström, Catharina. 2007. Queering Feminist Technology Studies. Feminist Theory 8, no. 1 (April): 7-26.

Latour, Bruno. 1987. Science in Action: How to Follow Scientists and Engineers Through Society. Harvard University Press.

Löwenheim, Oded. 2008. "Examining the State: A Foucauldian Perspective on International 'Governance Indicators'”. Third World Quarterly 29 (2): 255-274.

Maru, Yiheyis, Ashley Sparrow, Richard Stirzaker, and Jocelyn Davies. 2016. "Integrated Agricultural Research for Development (IAR4D) from a Theory of Change Perspective." Agricultural Systems, online 24 September.

Merry, Sally Engle. 2011. "Measuring the World: Indicators, Human Rights, and Global Governance." Current Anthropology 52 (S3): S83-95.

Mies, Maria. The Lace Makers of Narsapur. Spinifex Press, 2012.

Mukhopadhyay, Maitrayee. 1998. Legally Dispossessed: Gender, Identity and the Process of Law. Calcutta: Stree

Okali, Christine. 2012. "Gender Analysis: Engaging with Rural Development and Agricultural Policy Processes," Future Agricultures Working Paper 26. https://opendocs.ids.ac.uk/opendocs/bitstream/handle/123456789/23 18/FAC Working Paper 026.pdf?sequence=1\&isAllowed=y. Accessed 26 June 2018. 
Ortiz-Ferrara, G.; Bhatta, M.R.; Pokharel, T.; Mudwari, A.; Thapa, D.B.; Joshi, A.K.; Chand, R.; Muhammad, D.; Duveiller, E.; and Rajaram, S. 2001. "Farmer Participatory Variety Selection in South Asia." In Research Highlights of the CIMMYT Wheat Program, 1999-2000. Mexico, D.F.: CIMMYT.

Porter, Theodore M. Trust in Numbers: The Pursuit of Objectivity in Science and Public Life. Princeton, CT: Princeton University Press, 1996.

Prügl, Elisabeth. 2011. Diversity Management and Gender Mainstreaming as Technologies of Government. Politics \& Gender 7, no. 1 (March): 71-89.

Quisumbing, Agnes R., Ruth Meinzen-Dick, Terri L. Raney, André Croppenstedt, Julia A. Behrman, and Amber Peterman. 2014. Gender in Agriculture: Closing the Knowledge Gap. Springer Science \& Business.

Razavi, Shahra 2009. The Gendered impacts of Liberalization: Towards Embedded Liberalism? In Shahra Razavi ed. The Gendered impacts of Liberalization: Towards Embedded Liberalism? Routledge New York

Repo, Jemima. 2015. The Biopolitics of Gender. Oxford, New York: Oxford University Press.

Rose, Nikolas, and Peter Miller. 1992. "Political Power beyond the State: Problematics of Government." The British Journal of Sociology 43, no. 2 (June 1992): 173-205.

Rosga, AnnJanette, and Margaret L. Satterthwaie. 2009. "The Trust in Indicators: Measuring Human Rights." Berkeley Journal of International Law 27: 253 315.

Saugeres, Lise. 2002. "Of Tractors and Men: Masculinity, Technology and Power in a French Farming Community." Sociologia Ruralis 42 (2): 143-159.

Shiva, Vandana and J. Bandyopadhyay 1986. "The Evolution, Structure, and Impact of the Chipko Movement". ? Mountain Research and Development, Vol. 6, No. 2 (May, 1986), pp. 133-142

Strathern, Marilyn, ed. 2000. Audit Cultures: Anthropological Studies in Accountability, Ethics and the Academy. London: Routledge.

Stamp, Patricia, and IDRC. 1989. Technology, Gender, and Power in Africa. Ottawa: International Development Research Centre.

Thornton, PK, T Schuetz, W Förch, L Cramer, D Abreu, S Vermeulen, and BM Campbell. 2017. "Responding to Global Change: A Theory of Change Approach to Making Agricultural Research for Development OutcomeBased." Agricultural Systems 152 (March): 145-153.

Wajcman, Judy. 2013. TechnoFeminism. John Wiley \& Sons.

- - - 2000. "Reflections on Gender and Technology Studies: In What State Is the Art?" Social Studies of Science 30, no. 3 (June): 447-64.

Weber, Cynthia. 2016. Queer Intellectual Curiosity as International Relations Method: Developing Queer International Relations Theoretical and Methodological Frameworks. International Studies Quarterly 60, no. 1 (March): 11-23.

Woolgar, Steve, and Javier Lezaun. 2013. "The Wrong Bin Bag: A Turn to Ontology in Science and Technology Studies?" Social Studies of Science 43, no. 3 (June): 321-40.

World Bank. 2007. World Development Report 2008: Agriculture for Development. Washington, D.C.: World Bank. 
World Bank, FAO, and IFAD. 2008. Gender in Agriculture Sourcebook. The World Bank. http://elibrary.worldbank.org/doi/book/10.1596/978-0-82137587-7. Accessed 26 June 2018. 